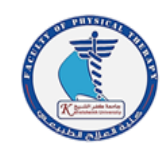

\title{
Value of soft tissue mobilization versus medical therapy in carpal tunnel syndrome treatment
}

\author{
Faten Ismail $^{1}$, Amal A Hassan', Rania M Mohammed', Rasha A Abdel-Magied ${ }^{1}$ \\ 1 Rheumatology and Rehabilitation department, Faculty of Medicine, Minia University, Egypt
}

\author{
*Correspondence to \\ Rasha Ali Abdel-Magied, \\ Department of \\ Rheumatology and \\ Rehabilitation, Faculty of \\ Medicine, Minia \\ University, Egypt \\ Tel: 00201202556774 \\ Fax: 0020862342503 \\ Email; \\ rashahazem@yahoo.com
}

Published online:

Sept 2021

\begin{abstract}
:
Purpose: to detect effectiveness of Soft tissue mobilization (STM) in reliving manifestations, improving function and electrophysiological studies of carpal tunnel syndrome (CTS) compared to medical treatment.

Methods: This single-blind randomized control study included sixty CTS-patients; 40 treated by STM and 20 received medical treatment only, STM of 18-treatments (3/week-for-6-weeks). Patients assessed clinically, functionally using Boston-CarpalTunnel-Questionnaire, Symptom-Severity-Scale (SSS) and Functional-Status-Scale (FSS) and electro-physiologically; sensory \& motor conduction tests of the median nerve. Assessment done at baseline and 6-weeks after treatment.

Results: Results showed that Significant difference within groups and by comparing both groups treated with STM and medical treatment after 6 weeks of treatment regarding tingling, extension \& flexion of wrist joint $(\mathrm{p} \leq 0.0001)$, Tinel sign $(\mathrm{p}=0.001)$, paresthesia \& Phalen test $(\mathrm{p}=0.01)$, awakening and pain $(\mathrm{p}=0.038)$. Significant difference within patients treated by STM with respect to SSS and FSS score and grade $(\mathrm{p} \leq 0.0001)$, similar findings could not be detected with medical treatment. SSS score and grade showed significant difference between patients in both groups $(p \leq 0.0001)$ and FSS score and grade $(p=0.001, p=0.004)$. Significant difference within patients treated by STM regarding nerve conduction studies; sensory distal latency, amplitude, conduction velocity $(\mathrm{p} \leq 0.0001)$, motor distal latency $(\mathrm{p}=0.004)$, motor amplitude $(\mathrm{p}=0.008)$ and change the grade of CTS $(\mathrm{p}=0.011)$. Patients received medical treatment showed significant difference only in sensory amplitude $(\mathrm{p}=0.036)$. Significant difference between both groups regarding change of the grade of CTS $(\mathrm{p}=0.03)$.

Conclusion: Clinical, functional and electrophysiological changes in post-STM treated CTS patients have been better than medical therapy alone; thereby offering a satisfactory evidence to justify the use of manual therapy in conservative management of CTS.
\end{abstract}

Key words: Carpal tunnel syndrome (CTS); Manual therapy; Nerve conduction study; Soft tissue mobilization (STM).

\section{Introduction}

The most common peripheral neuropathy that occur in the upper limb due to wrist-locking of the median nerve is carpal tunnel syndrome (CTS) (1). Symptoms in most CTS patients are self-limiting and respond to non-operative conservative therapies; including rest, anti-inflammatory drugs, alteration of physical activities, splinting, and techniques of manual therapy $(2,3)$. Conservative therapies should be taken into account as the first care choice for patients with mild to moderate degrees of CTS (4-8). 
The malfunction of the mechanical structures around the nerve and nerve itself should be the subject of care $(9,10)$. Manual therapy strategies that were designed to mechanical interfaces to relive the mechanical compression around the median nerve by releasing tissue adhesions and increasing the wrist joint range of motion (ROM). The patho-mechanism of CTS should take into account the mechanical structures that surround the median nerve at the wrist (such as flexor tendons in the carpal tunnel and the transverse carpal ligament) and other structures that surround the median nerve in proximal regions of the upper limb (9). Increased joint movement will increase the flow of blood inside the vasa nervorum, thereby reducing the local ischemic effects on the median nerve encouraging the regeneration and healing of the nerve $(3,9)$.

Manual therapy of the median nerve includes; soft tissue mobilization (STM), carpal bone mobilization and median nerve mobilization (2).

\section{Patients and Methods}

\subsection{Study participants and recruitment criteria:}

The study included sixty idiopathic CTS patients that were clinically and electrophysiologically proven. The patients were all female housewives with unilateral CTS. Thirty-six patients with moderate degree CTS and twenty-four patients with mild degree CTS based on the electrophysiological tests. Patients were recruited in the period of 6 months, treated for 6 weeks and follow up done after 6 weeks of treatment. The included patients were blocked randomized in a 2:1 ratio into 2 groups via computer based "random number generator" using the GraphPad QuickCalcs Website.

\subsection{Study Design:}

A single-blind randomized control study.

Based on the treatment received, patients were divided in to two categories. Group I: Includes 40 patients treated by Soft tissue mobilization (STM) (24 with moderate and 16 with mild CTS) and group II: Includes 20 patients with medical drugs only (NSAIDs, diclofenac $150 \mathrm{mg}$ per day for 2 weeks and vitamin B12 1500 microgram/day for 6 weeks) (12 with moderate and 8 with mild CTS). Additional treatment such as splints, steroid injection, other physical modalities were not allowed during the study. The treatment was received for 6 weeks. All patients were assessed at base line and after 6 weeks of treatment.

The study protocol was approved by the local Ethics Committee of Faculty of Medicine and in agreement to the World Medical Association Declaration of Helsinki. The nature of the study was explained to all included patients and an informed consent was obtained. Excluded from the study patients with; prior carpal tunnel surgery, physically treated or locally injected patient, CTS secondary to underlying cause or other musculoskeletal condition.

\subsection{Assessment:}

History and detailed clinical evaluation with attention to paresthesia, tingling, pain, night awakening, wrist joint flexion and extension that were assessed by goniometer, sensation of the hand, hand strength, thenar eminence hypotrophy, Phalen test (wrist flexion test) was considered positive when paraesthesia in the median nerve territory was triggered by complete wrist flexion for 60 seconds (11). Tinel sign: positive Tinel's sign is defined as tingling sensation in a particular anatomic distribution, that occurs because of light percussion over the median nerve (12). Clinical evaluation was at base line and reviewed at the end of the $6^{\text {th }}$ weeks of treatment.

The severity of symptom and the functional status were evaluated using the validated Boston Carpal Tunnel Questionnaire (BCTQ). It is the most widely used outcome test for the evaluation of clinical symptoms improvements and functional recovery in CTS patients (13). The BCTQ has been used for the evaluation of severity and function at base line and reviewed at the end of the $6^{\text {th }}$ weeks of treatment. The two subscales comprise the questionnaire are the Symptom Severity Scale (SSS) and the Functional Status Scale (FSS). The SSS comprises of eleven questions that addressed the clinical symptoms of CTS patients which are; severity of nocturnal pain, frequency of nocturnal awakening caused by pain, daytime pain severity, daytime pain frequency, daytime pain duration, severity of numbness, severity of weakness, severity of tingling, nocturnal numbness/tingling severity, frequency of nocturnal awakening caused by numbness/tingling, and difficulty in gripping of small objects. The SSS graded for the degree of difficulty on five-point scale, with each symptom scored from 1 (mildest) to 5 (most severe). The average ranking for the eleven items represents the overall SSS. FSS consisted of 8 everyday tasks performed by most people with CTS; writing, holding book, buttoning of clothes, telephone gripping, jars opening, household chores performing, grocery bag carrying, bathing $\&$ dressing. The patients assessed for the degree of difficulty on a five-point scale that ranging from 1 (no difficulty with the task) to 5 (cannot perform the task at all). The average of scores on the eight daily tasks was the total FSS. According to their mean rating score; patients were split into five groups: extreme (4.1-5 points), severe 
(3.1-4 points), moderate (2.1-3 points), mild (1.1-2 points) and minimal (0.1-1 point).

The patient's self-assessed degree of pain using Visual Analogue Scale (VAS) (14), on which the patients can be assessed over a distance of $10 \mathrm{~cm}$, varying from 0 (no pain) to 10 (most intense pain).

Median nerve sensory nerve conduction velocity (SNCV) and distal motor latency (DML) electrophysiologic tests of the were performed in all patients and control at base line and reviewed at the end of the $6^{\text {th }}$ weeks of treatment: The detection of severity of CTS was taken after the guidelines of the American Association of Neuromuscular and Electrodiagnostic Medicine (15) and American Academy of Orthopedic Surgeons (AAOS) (16) as follows; negative: normal results for all tests (including comparative and segmental studies), minimal: abnormal results for comparative or segmental tests only, mild: SNCV slowed with normal $\mathrm{DML}$ in the finger-wrist tract, moderate: SNCV slowed with increased DML in the finger-wrist tract, severe: absence of sensory response with increased DML in the finger-wrist tract, extreme: absence of the motor response thenar muscles.

\subsection{Intervention:}

For patients in group I, soft tissue mobilization (STM) $(2,3,8,17,18)$ was performed. Patients were scheduled for 6 weeks to undergo 3 sessions / week (total of 18 treatment); Manual STM of the forearm-wrist-hand areas was performed by the clinician's hands to break down the scar tissue and any fascial restrains. The relaxed forearm-wrist-hand of the patients was rested on the treatment table during the manual STM treatment, and the clinician applied deep intense finger pressure of both hands to the scar tissue, taut muscle bands, stretched connective tissue and myofascial restrictions. Five techniques were applied including; distraction of the wrist (3 sets for 3 minutes), transverse carpal ligaments rhythmic and gentle stretching, release of palmar hand fascia, finger flexor tendons gliding (using metacarpophalangeal joint oscillatory flexion- extension movement) and upper forearm muscle and fascial release (a firm pressure was exerted by the therapist using one thumb on the origin of the pronator teres muscle while simultaneously the forearm is moved into extension and supination). Manual techniques were performed for a total of 15 minutes and each technique included 3 sets for 3 minutes.

\section{DATA ANALYSIS:}

The data were analyzed using the statistical package for social sciences (SPSS Inc., Chicago, IL, USA) version 16.0.0. Numbers / percentage (percent) and mean \pm SD were respectively known as categorical and quantitative variables. The Mann Whitney or Chi-squared (x2) measures were used to compare variables. The statistical significance level was set at a level of $p$ value less than 0.05 .

\section{RESULTS:}

Sixty patients were included in the research, with a mean \pm SD age ranging from 17 to 55 years $(34.05 \pm$ 10.19). The disease duration varied from 4 to 16 months with a mean \pm SD $(12.0 \pm 3.5)$.

According to the method of treatment, the patients were divided in to two categories. Group I includes 40 unilateral CTS patients treated with STM; 16 milddegree CTS patients and 24 moderate-degree CTS patients, group II: includes 20 unilateral CTS patients treated with medical treatment only; 8 mild-degree CTS patients and 12 moderate-degree CTS patients.

Paresthesia, tingling, pain, wakening at night, positive Phalen and Tinel tests were conducted in all patients in group I and group II. All patients in group II had impaired sensation (hypothesis) while this was detected in 30 patients (75\%) in group I. Patients were assessed before and treatment in each group according to clinical data, BCTQ and nerve conduction studies.

Regarding clinical data; it showed significant difference within the group and by comparing both groups treated with STM and medical treatment after 6 weeks of treatment. There was significant difference between patients in both groups regarding tingling, flexion \& extension of wrist joint $(\mathrm{p} \leq 0.0001)$, Tinel sign $(\mathrm{p}=0.001)$, paresthesia and Phalen test $(\mathrm{p}=0.01)$, awakening and pain $(\mathrm{p}=0.038)$. There was no significant difference at strength (table 1).

There was significant improvement in VAS within both groups before and after treatment $(p \leq 0.0001)$ and significant difference between both groups ( $\mathrm{p}=0.003$ ).

There was significant difference within patients in group I treated by STM with respect to SSS score and grade and FSS score and grade $(\mathrm{p} \leq 0.0001)$, similar findings could not be detected in group II treated with medical treatment, as there was improvement but did not reach significant level. There was significant difference between patients in both groups regarding SSS score and grade $(\mathrm{p} \leq 0.0001)$ and FSS score and grade ( $\mathrm{p}=0.001, \mathrm{p}=0.004$ ) (table 2, figure 1,2$)$.

There was significant difference within patients in group I treated by STM after 6 weeks of treatment regarding nerve conduction studies; sensory distal latency, sensory amplitude, sensory conduction velocity $(\mathrm{p} \leq 0.0001)$, motor distal latency $(\mathrm{p}=0.004)$, motor 
Table 1: Clinical data of CTS patients before and after treatment:

\begin{tabular}{|c|c|c|c|c|c|c|}
\hline \multirow[b]{2}{*}{ Clinical Data } & \multirow[b]{3}{*}{ base line } & \multicolumn{2}{|c|}{$\begin{array}{l}\text { Group I } \\
40 \text { patients } \\
\text { (STM) }\end{array}$} & \multicolumn{2}{|c|}{$\begin{array}{c}\text { Group II } \\
20 \text { patients } \\
\text { (medical treatment) }\end{array}$} & \multirow{2}{*}{$\begin{array}{c}\text { group I } \\
\text { versus group } \\
\text { II } \\
x^{2} / t \\
\text { p value }\end{array}$} \\
\hline & & $\begin{array}{c}\text { no }(\%) \\
\text { range (mean } \pm \\
\text { SD) }\end{array}$ & $\begin{array}{c}x^{2} / t \\
\mathrm{p} \text { value }\end{array}$ & $\begin{array}{c}\text { no }(\%) \\
\text { range (mean } \pm \\
\text { SD) }\end{array}$ & $\begin{array}{c}x^{2} / t \\
\text { p value }\end{array}$ & \\
\hline \multirow[t]{2}{*}{ Sensation } & & $30(75)$ & 24.00 & $20(100 \%)$ & 20.00 & \\
\hline & after 6 weeks & 0 & $\leq 0.0001$ & 0 & $\leq 0.0001$ & $\begin{array}{l}1.825 \\
0.145\end{array}$ \\
\hline \multirow[t]{2}{*}{ Paresthesia } & base line & $40(100)$ & 24.00 & $20(100 \%)$ & 10.77 & \\
\hline & after 6 weeks & 0 & $\leq 0.0001$ & $6(30 \%)$ & 0.001 & $\begin{array}{c}6.677 \\
\mathbf{0 . 0 1}\end{array}$ \\
\hline \multirow[t]{2}{*}{ Tingling } & base line & $40(100)$ & 40.00 & $20(100 \%)$ & 5.00 & \\
\hline & after 6 weeks & 0 & $\leq 0.0001$ & $12(60 \%)$ & 0.025 & $\begin{array}{c}15.00 \\
\leq \mathbf{0 . 0 0 0 1}\end{array}$ \\
\hline \multirow[t]{2}{*}{ Pain } & base line & $40(100)$ & 40.00 & $20(100 \%)$ & 13.33 & \\
\hline & after 6 weeks & 0 & $\leq 0.0001$ & $4(20 \%)$ & $\leq 0.0001$ & $\begin{array}{c}4.286 \\
\mathbf{0 . 0 4}\end{array}$ \\
\hline \multirow[t]{2}{*}{ Phalen test } & base line & $40(100)$ & 40.00 & $20(100 \%)$ & 10.77 & \\
\hline & after 6 weeks & 0 & $\leq 0.0001$ & $6(30 \%)$ & 0.001 & $\begin{array}{c}6.677 \\
\mathbf{0 . 0 1}\end{array}$ \\
\hline \multirow[t]{2}{*}{ Tinel sign } & base line & $40(100)$ & 36.19 & $20(100 \%)$ & 5.00 & \\
\hline & after 6 weeks & 0 & $\leq 0.0001$ & $12(60 \%)$ & 0.025 & $\begin{array}{c}11.273 \\
\mathbf{0 . 0 0 1}\end{array}$ \\
\hline \multirow[t]{2}{*}{ Extension } & base line & $(60-73)$ & -6.789 & $(65-72)$ & -0.438 & \\
\hline & after 6 weeks & $\begin{array}{c}66.8 \pm 3.3 \\
(69-78)\end{array}$ & $\leq 0.0001$ & $\begin{array}{c}68.8 \pm 1.9 \\
(65-73)\end{array}$ & 0.667 & $\begin{array}{c}4.134 \\
\leq \mathbf{0 . 0 0 0 1}\end{array}$ \\
\hline \multirow[t]{3}{*}{ Flexion } & base line & $\begin{array}{c}73.2 \pm 2.6 \\
(55-68)\end{array}$ & -6.487 & $\begin{array}{c}69.2 \pm 2.2 \\
(60-68)\end{array}$ & -0.514 & \\
\hline & after 6 weeks & $\begin{array}{c}62.5 \pm 3.8 \\
(65-73)\end{array}$ & $\leq 0.0001$ & $\begin{array}{c}64.6 \pm 2.2 \\
(60-68)\end{array}$ & 0.614 & $\begin{array}{l}4.502 \\
\leq \mathbf{0 . 0 0 0 1}\end{array}$ \\
\hline & & $68.8 \pm 2.1$ & & $65.1 \pm 2.2$ & & \\
\hline
\end{tabular}

amplitude $(\mathrm{p}=0.008)$ and the change of the grade of CTS $(p=0.011)$. In patients in group II who received medical treatment only; there was significant difference in sensory amplitude only ( $\mathrm{p}=0.036)$ after 6 weeks of treatment. There was significant difference between patients in both groups with respect to changes of CTS grade $(\mathrm{p}=0.03$ ) (table 3 , figure 3 ).

\section{DISCUSSION:}

Several treatment options both surgical and conservative, are available to alleviate the pressure of the median nerve at the wrist (8). As a reasonable first step, conservative treatment with CTS should be highlighted because it can be effective in management of mild to moderate CTS (19). 
Table 2: Boston Carpal Tunnel Questionnaire in CTS patients before and after treatment

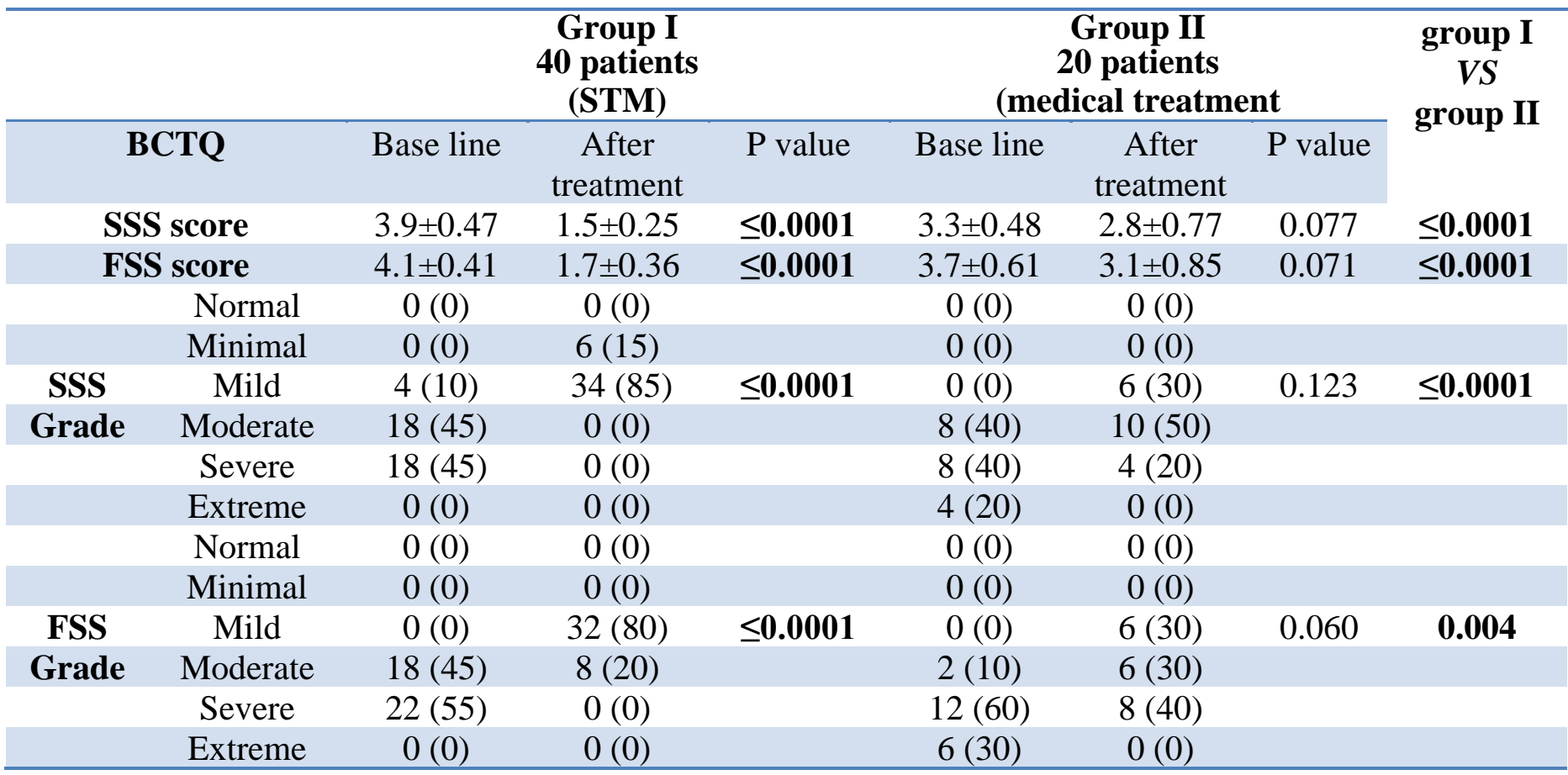

Table 3: Nerve conduction studies in CTS patients before and after treatment.

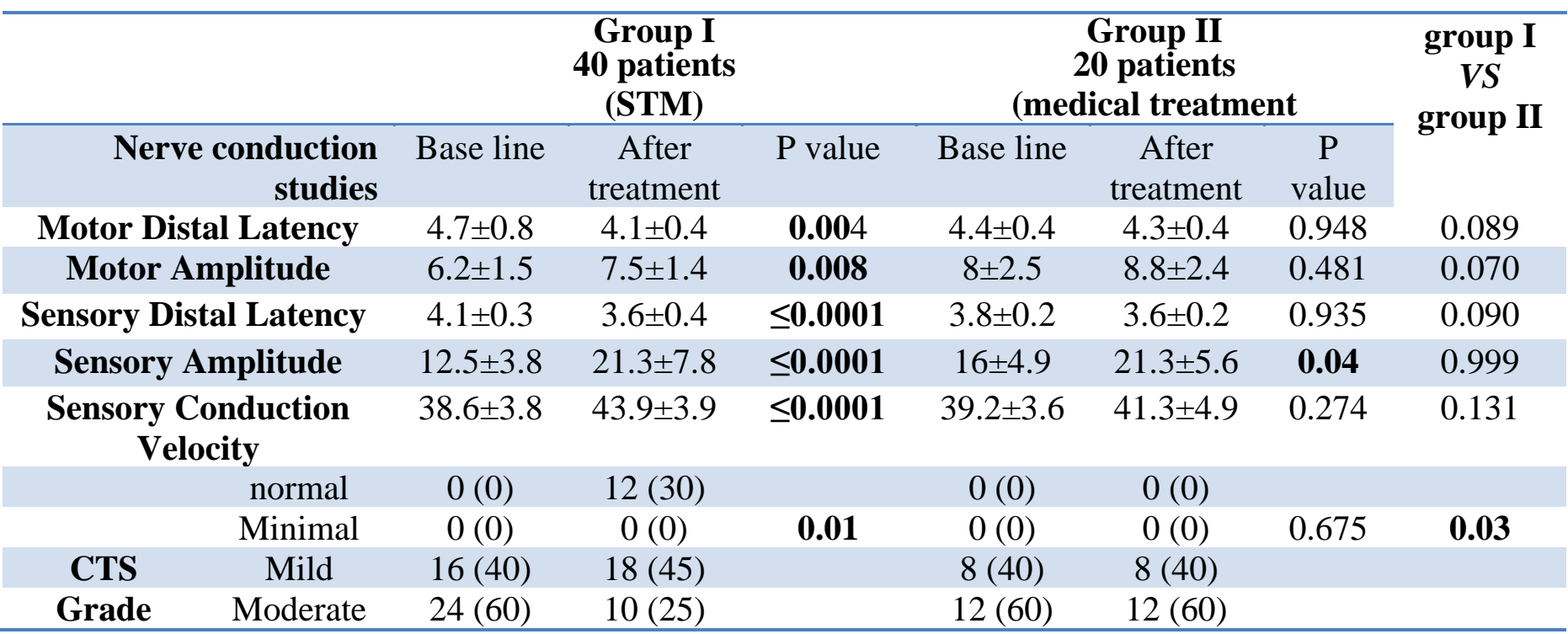

This research showed that patients undergoing STM are substantially improved significantly in clinical symptoms (paresthesia, strength, awakening, tingling and pain, Phalen test, Tinel sign, ROM of wrist joint (extension \& flexion)), pain measurements (VAS) and functional assessment (FSS and SSS score and grade), which indicate that there is substantial improvement in pain reduction and CTS disability. There was also significant difference with respect to electrophysiological studies and the improvement in the CTS grade.

The research of Talebi et al., (1) agreed with our findings, as they found that manual therapy technique which is directed to mechanical interface of the median nerve for four weeks led to reduction of the pain severity and improvement of both the SSS and FSS in CTS patients significantly, but they cannot find significant effects on electrodiagnostic parameters 


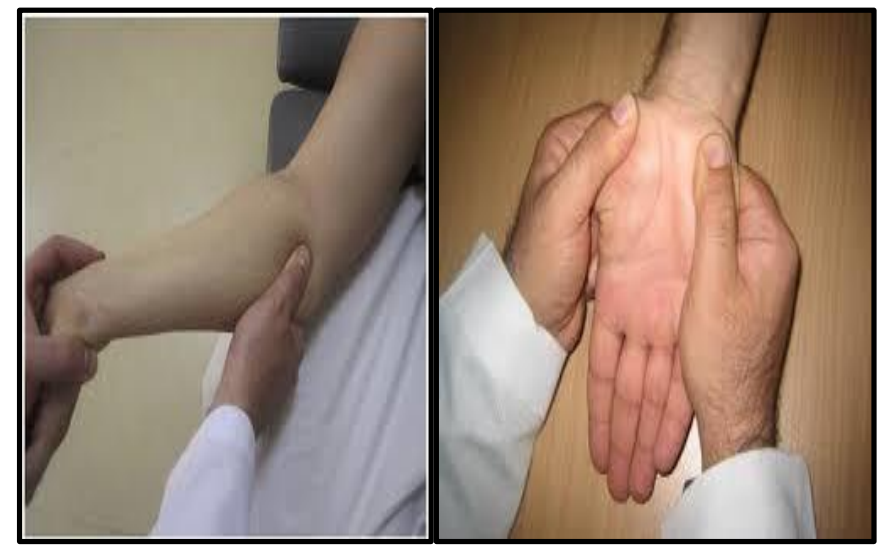

Figure 1: Soft tissue manipulation of the median nerve: a) Transverse carpal ligament release, b) Soft tissue manipulation of the pronator teres.

(sensory and motor latencies of median nerve), the difference in this point from our study may be due to the short duration of the intervention as their patients undergo manual manipulation for 4 weeks only (3 sessions/week) for a total 12 treatment, so they proved that manual therapy technique has beneficial and positive effects on clinical symptoms improvement in patients with CTS. Also, Oskouei et al., (20) suggested that 4-week treatment with manual therapy, including flexor retinaculum and transverse carpal ligaments stretching, tendon gliding techniques and mobilization of the median nerve, along with physiotherapy modalities including the ultrasound and TENS, resulted in a substantial improvement of VAS, SSS, FSS, median neurodynamic studies and sensory latency of median nerve in CTS patients. The research conducted by Bongi et al., (2) using soft tissue mobilization for 3 weeks ( 2 sessions/ week), patients were found to significantly improved in hand symptoms such as paresthesia, strength, awakening, tingling, pain and they proved that STM decreases tissue adhesion and increases wrist ROM. Their findings also showed that SSS and FSS scores were declined. However, while STM was successful in relieving symptoms in their studies, they found that the therapy did not enhance nerve conduction measurements nor change neurophysiological CTS grading, this may be due to the short duration of the intervention as they treated their patients for a total 6 treatments for 3 weeks with manual manipulation (2 sessions/week).

In another study, Burke et al., (3) stated that manual therapy (either instrument-assisted STM or manual STM, both combined with strengthening and stretching home exercises), by means of deep manual pressure on scar tissue and tight muscle, stretching of the connective tissues and fascia of the hand, wrist and forearm (interventions were conducted on a total six of weeks; an average of twice a week for 4 weeks and once a week for another 2 additional weeks), resulted in significantly improvement of the CTS symptoms, median nerve motor and sensory latencies, VAS, SSS, FSS, grip strength and wrist joint range of motion patients with mild to moderate-degree CTS, so the clinical effectiveness of conservative treatment for mild to moderate-degree of CTS is thus endorsed. In a study of George et al., (21) at the open-label research conducted on a small cohort of CTS-affected patients with, STM (administered 3 times per week for 2 weeks) was performed, improving patients' symptoms and functional status that was assessed by BCTQ.

In a case study by Baker and Wilson, (22) which investigated the benefit of STM in the management of patients with bilateral CTS, it was found that STM was shown to be an effective treatment method for improving the patient's symptoms. Seradge et al., (23) have argued that one minute of intermittent active wrist and finger exercise can reduce the pressure inside the carpal tunnel. Also, in the research by Valente and Gibson, (17), where they used STM in treatment of their patients, symptoms relief was also observed in patients with CTS.

\section{CONCLUSION:}

patients with CTS may improve after STM, which was better than patients receiving medical treatment only, and thus provides encouragement for the use of manual therapy in the conservative management methods with acceptable results for the treatment of patients with this condition. In order to postpone or avoid disease progression and subsequent surgical procedure, the advantage of manual therapy is better identified within a particular population with mild and moderate CTS.

\section{Limitations of the study:}

Small number of patients included in the study, also the study was not registered in any public data base.

\section{DECLARATION OF INTERSEST:}

There is no conflict of interest that could be perceived as prejudicing the impartiality of the research reported.

\section{FUNDING:}

This research did not receive any specific grant from any funding agency in the public, commercial or not-for-profit sector.

\section{AKNOWLEDGMENT:}

To all who shared in the study. 


\section{SSS grade in group I and group II at base line and after treatment}

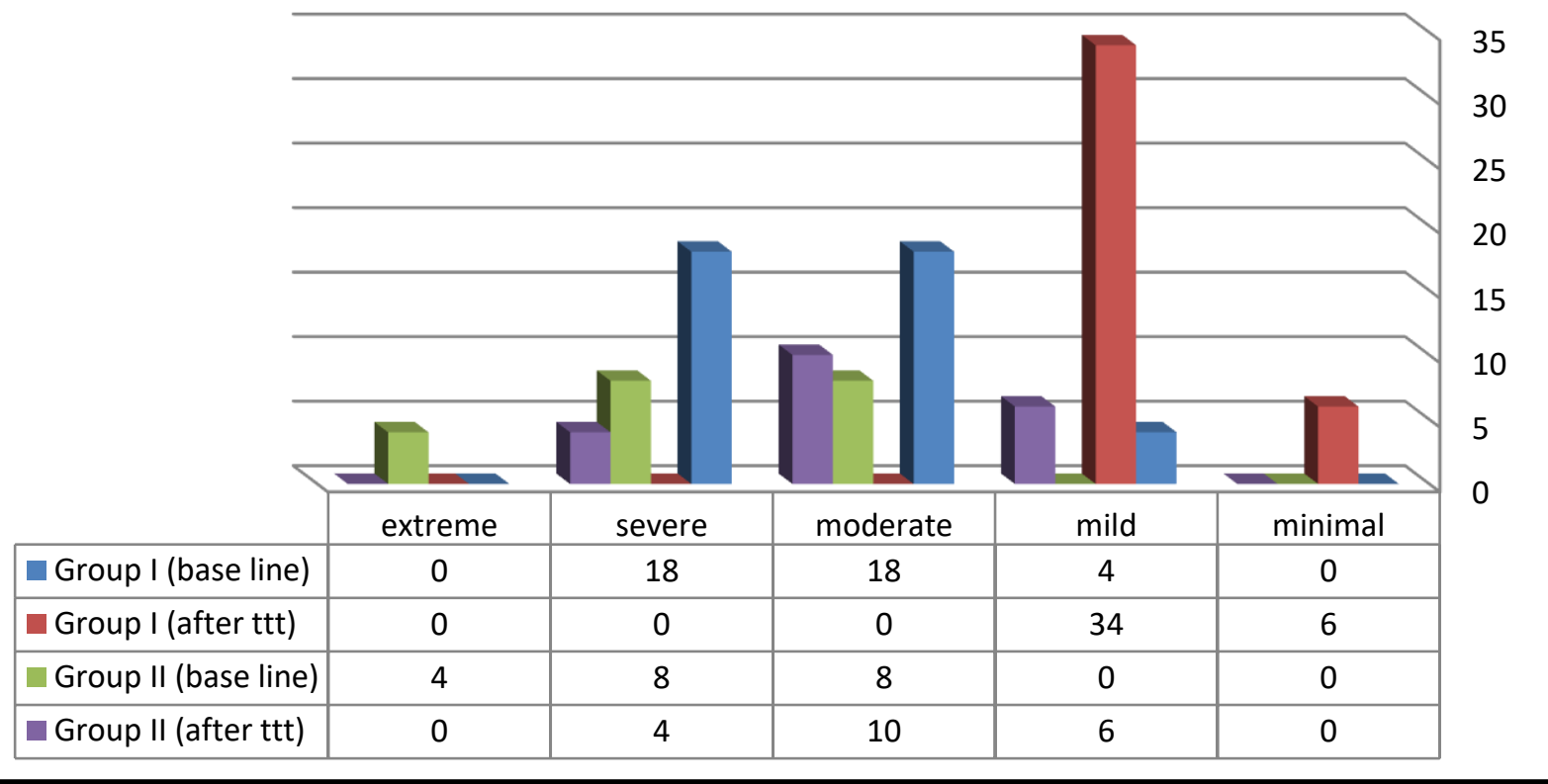

Figure 2: SSS grade in CTS patients before and after treatment

\section{FSS grade in group I and group II at base line and after treatment}

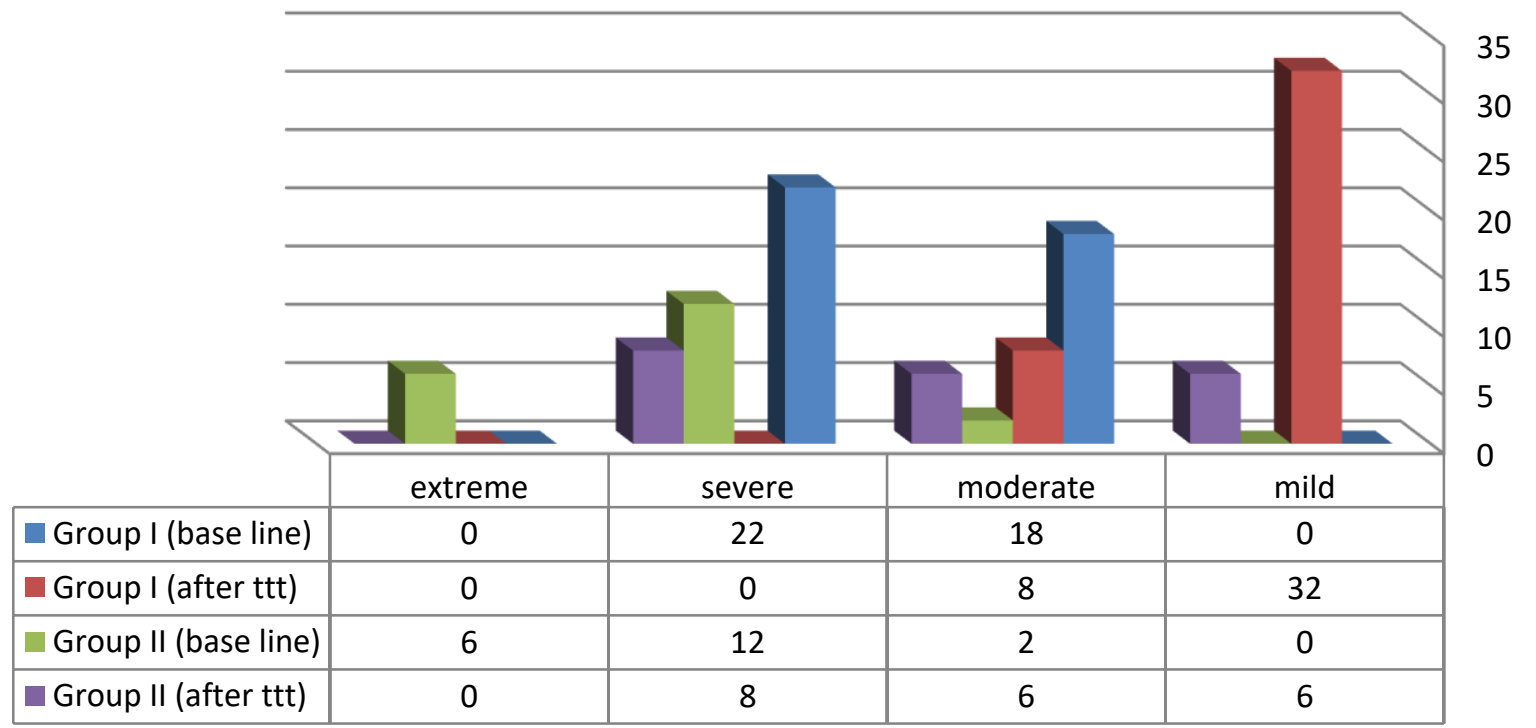

Figure 3: FSS grade in CTS patients before and after treatment 


\section{CTS grade in group I and group II at base line and after treatment}

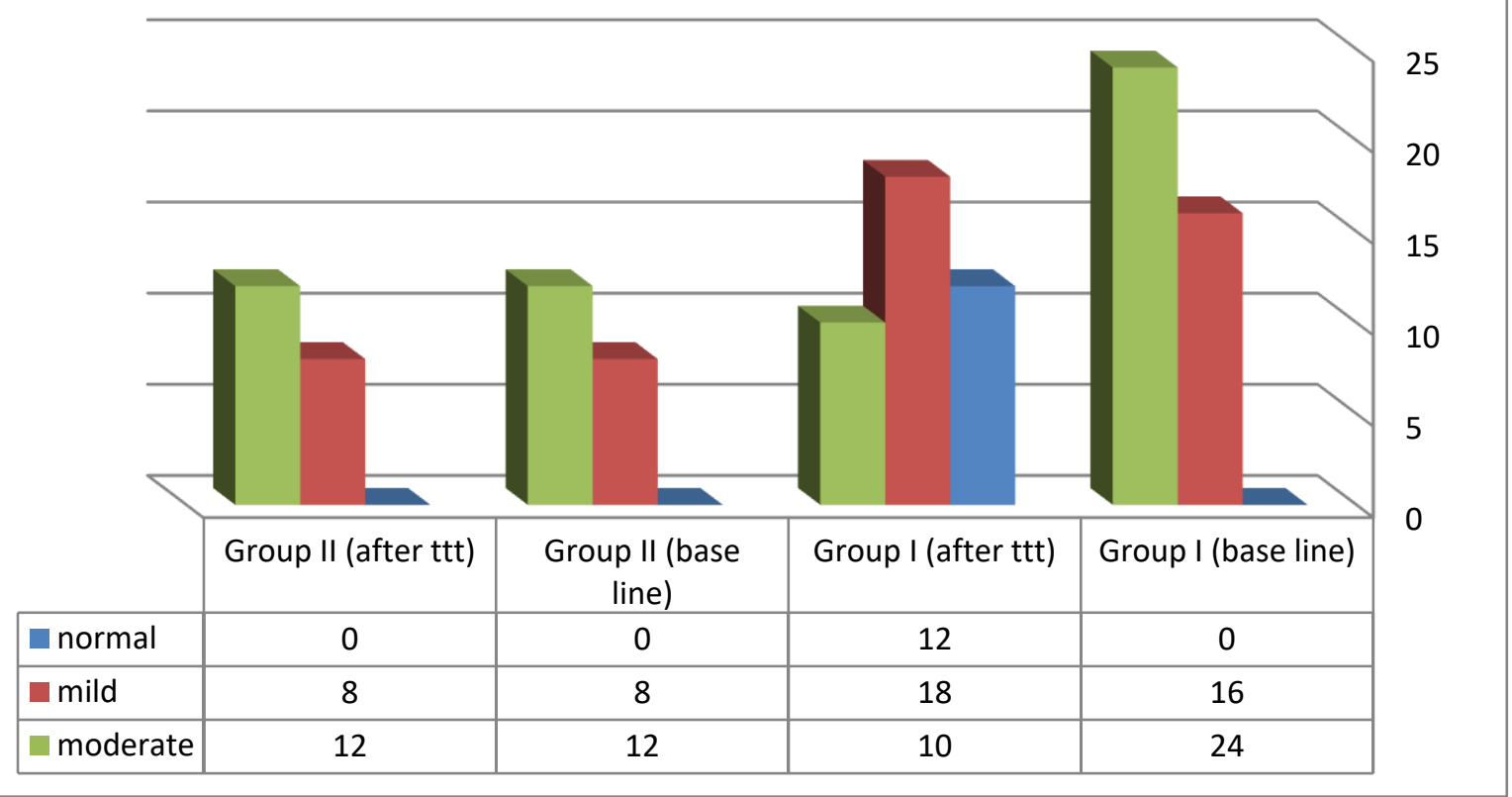

Figure 4: CTS grade in CTS patients before and after treatment.

\section{References}

1. Talebi GA, Saadat P, Javadian Y, Taghipour M. Comparison of two manual therapy techniques in patients with carpal tunnel syndrome: A randomized clinical trial. Caspian Journal of Internal Medicine. 2020;11(2):163.

2. Bongi SM, Signorini M, Bassetti M, Del Rosso A, Orlandi M, De Scisciolo G. A manual therapy intervention improves symptoms in patients with carpal tunnel syndrome: a pilot study. Rheumatology international. 2013 May 1;33(5):1233-41.

3. Burke J, Buchberger DJ, Carey-Loghmani MT, Dougherty PE, Greco DS, Dishman JD. A pilot study comparing two manual therapy interventions for carpal tunnel syndrome. Journal of manipulative and physiological therapeutics. 2007 Jan 1;30(1):50-61.

4. Michlovitz SL. Conservative interventions for carpal tunnel syndrome. J Orthop Sports Phys Ther. 2004; 34:589-600.

5. Ebenbichler GR, Resch KL, Nicolakis $P$, Wiesinger GF, Uhl F, Ghanem AH, et al. Ultrasound treatment for treating the carpal tunnel syndrome: randomised "sham" controlled trial. BMJ. 1998; 316:731-735.

6. Naeser MA, Hahn KA, Lieberman BE, Branco KF. Carpal tunnel syndrome pain treated with low-level laser and microamperes transcutaneous electric nerve stimulation: a controlled study. Arch Phys Med Rehabil. 2002; 83:978-88.

7. Baysal O, Altay Z, Ozcan C, Erteme K, Yologlu S, Kayhan A. Comparison of three conservative treatment protocols in carpal tunnel syndrome. Int J Clin Pract. 2006; 60:820-8.

8. Gerritsen AA, De Vet HC, Scholten RJ, Bertelsmann FW, De Krom MC, Bouter LM. Splinting vs surgery in the treatment of carpal tunnel syndrome: a randomized controlled trial. Jama. 2002 Sep 11;288(10):1245-51.

9. Shacklock M. Clinical neurodynamics: a new system of musculoskeletal treatment. Oxford: Elsevier; 2005. ISBN-13: 978-0750654562.

10. Oskouei AE, Talebi GA, Shakouri SK, Ghabili $\mathrm{K}$. Effects of neuromobilization maneuver on clinical and electrophysiological measures of patients with carpal tunnel syndrome. Journal of physical therapy science. 2014;26(7):101722.

11. Seror P. Phalen's test in the diagnosis of carpal tunnel syndrome. J Hand Surg Br 1988; 13:383-385. 
12. Seror P. Tinel's sign in the diagnosis of carpal tunnel syndrome. J Hand Surg [Br]. 1987; 12:364-365.

13. Levine DW, Simmons BP, Koris MJ, Daltroy LH, Hohl GG, Fossel AH, et al. A selfadministered questionnaire for the assessment of severity of and functional status in carpal tunnel syndrome. J Bone Joint Surg Am 1993;75(11):1585-1892.

14. Collins SL, Moore RA, and McQuay HJ. The visual analogue pain intensity scale; what is moderate pain in millimetres? Pain 1997; 72:95-97.

15. England JD, Gronseth GS, Franklin G, Carter GT, Kinsella LJ, Cohen JA et al. Practice parameter: the evaluation of distal symmetric polyneuropathy: the role of laboratory and genetic testing (an evidence-based review). Report of the American Academy of Neurology, the American Association of Neuromuscular and Electrodiagnostic Medicine, and the American Academy of Physical Medicine and Rehabilitation. PM R 2009; 1:5-13.

16. Keith MW, Masear V, Chung K, Maupin K, Andary M, Amadio PC, et al. Diagnosis of carpal tunnel syndrome. J Am Acad Orthop Surg 2009;17(6):389-96.

17. Valente $R$ and Gibson $H$. Chiropractic Manipulation in Carpal Tunnel Syndrome. Journal of Manipulative and Physiological Therapeutics 1994;17(4): 246-249.

18. Talebi GA, Saadat P, Javadian Y, Taghipour M. Manual therapy in the treatment of carpal tunnel syndrome in diabetic patients: A randomized clinical trial. Caspian J Intern Med. 2018; 9:283-9.

19. Feuerstein M, Burrell LM, Miller VI, Lincoln A, Huang GD, and Berger R. Clinical management of carpal tunnel syndrome: a 12year review of outcomes. American Journal of Industrial Medicine 1999; 35: 232 - 245.

20. Oskouei AE, Talebi GA, Shakouri SK, Ghabili $\mathrm{K}$. Effects of neuromobilization maneuver on clinical and electrophysiological measures of patients with carpal tunnel syndrome. J Phys Ther Sci. 2014; 26:1017-1022.

21. George JW, Tepe R, Busold D, Keuss S, Prather $\mathrm{H}$, and Skagges CD. The effects of active release technique on carpal tunnel patients: a pilot study. J Chirpor Med 2006; 5:119-122.

22. Baker D and Wilson JK. Bilateral carpal tunnel syndrome in a piano teacher. Physical Therapy Case Reports 1999; 2(2):73-76.
23. Seradge H, Jia YC, Owens W. In vivo measurement of carpal tunnel pressure in the functioning hand. J Hand Surg. 1995; 20:8559. 